\title{
PERSEPSI DUNIA KERJA TERHADAP LULUSAN FRESH GRADUATE S1 MENGGUNAKAN MULTIDIMENSIONAL UNFOLDING (Studi Kasus: Dunia Usaha di Kabupaten Batang)
}

\author{
M. Atma Adhyaksa', Agus Rusgiyono ${ }^{2}$ \\ ${ }^{1}$ Alumni Program Studi Statistika FMIPA UNDIP \\ ${ }^{2}$ Staf Pengajar Program Studi Statistika FMIPA UNDIP
}

\begin{abstract}
Corporate perception of college graduates S1 fresh graduate is a viewpoint held by the world of work regarding the criteria considered in selecting candidates for most job applicants from graduates S1 fresh graduate based on his resume. Perceptions are reviewed based on the configuration of unfolding multidimensional mapping between business entities with the most preferred criteria in the selection process beginning college graduates S1 fresh graduate. Multidimensional unfolding was one of the techniques used in analyzing the proximity between objects is visualized in graphical form in which individuals and stimuli presented in one graph. The result is a grade point average, ability and suitability of computer applications course with the working position is most noticed by companies in selecting a job application letter from the college graduates $\mathrm{S} 1$ fresh graduate.
\end{abstract}

Keywords: Corporate Perception, Fresh Graduate, Multidimensional Unfolding

\section{Pendahuluan}

Dewasa ini, pendidikan di Indonesia mendapat tantangan yang tidak ringan. Tidak sedikit lulusan perguruan tinggi yang memiliki nilai bagus bingung terhadap apa yang harus mereka lakukan ketika kembali ke masyarakat. Terdapat juga lulusan perguruan tinggi yang merasa dirinya belum siap dan mampu dalam melangkah untuk memasuki dunia kerja, terutama pada lulusan baru (fresh graduate). Disamping itu lapangan kerja yang tersedia sepertinya tidak mampu menampung seluruh pencari kerja yang jumlahnya terus meningkat. Situasi ini pada akhirnya menempatkan para pencari kerja dalam posisi yang kurang menguntungkan, karena pihak perusahaan akan semakin ketat dalam menyaring tenaga kerja dan pada akhirnya hanya bersedia merekrut tenaga kerja - tenaga kerja yang handal dan profesional. Di tengah posisi tawar yang semakin rendah, para sarjana harus menghadapi persaingan yang sangat ketat untuk memperebutkan posisi pekerjaan yang tersedia. Akibatnya banyak pengangguran terdidik sampai pada tingkat titik jenuh, diperparah lagi kondisi ekonomi yang tidak menentu seperti sekarang ini, maka lapangan kerja semakin sempit. Mencermati ketatnya persaingan dunia kerja pada saat sekarang ini, tidak hanya perguruan tinggi yang dituntut untuk mampu mendidik mahasiswanya dengan tepat dan benar sesuai perkembangan zaman, para mahasiswa dan calon mahasiswa pun diharuskan mampu untuk dapat mempersiapkan diri dengan baik, agar nantinya ketika lulus mereka merupakan lulusan yang berkualitas, berdaya saing dan mampu menghadapi perkembangan zaman yang cepat berubah. Salah satu bentuk persiapan tersebut adalah dengan mengetahui bagaimana persepsi dunia kerja terhadap lulusan perguruan tinggi, dalam hal ini mengetahui faktor apakah yang sangat dibutuhkan bagi lulusan perguruan tinggi fresh graduate S1. Pertama-tama yang dilakukan oleh para lulusan perguruan tinggi fresh graduate S1 untuk masuk ke dunia kerja adalah mengirimkan lamaran pada perusahaan yang ingin dimasuki. Oleh pihak perusahaaan, 
surat lamaran yang masuk akan diseleksi berdasarkan kriteria-kriteria yang sudah ditentukan. Terdapat beberapa kriteria awal yang dipertimbangkan perusahaan ketika akan merekrut lulusan fresh graduate S1 antara lain seperti indek prestasi kumulatif, kemampuan bahasa inggris, kesesuaian program studi dengan posisi kerja, nama besar perguruan tinggi, pengalaman magang, pengalaman organisasi, dan lain sebagainya.

Salah satu cara untuk membandingkan persepsi berbagai kategori badan usaha terhadap lulusan perguruan tinggi fresh graduate S1, dalam hal ini membandingkan kriteria awal yang dipertimbangkan antar kategori perusahaan ketika akan merekrut lulusan fresh graduate S1 berdasarkan surat lamaran yang diajukan, adalah dengan menggunakan Analisis Multidimensional Unfolding. Multidimensional Unfolding (MDU) merupakan salah satu teknik yang digunakan dalam menganalisis kedekatan antar individu dan atribut/stimuli berdasarkan nilai yang diberikan tiap individu mengenai tiap atribut ${ }^{[3]}$, dalam hal ini nilai yang diberikan tiap badan usaha terhadap kriteria awal pelamar. Hasil akhir yang diperoleh merupakan visualisasi data berupa gambar/peta koordinat poin-poin tiap badan usaha/perusahaaan dan tiap kriteria awal pelamar yang merepresentasikan kedekatan berbagai jenis badan usaha dengan faktor yang diutamakan ketika merekrut karyawan dari lulusan perguruan tinggi fresh graduate S1.

\section{Tinjauan Pustaka}

\subsection{Lulusan Perguruan Tinggi}

Pengangguran di negeri ini luar biasa besarnya dan lulus dari perguruan tinggi (sarjana) ternama pun tidak selalu menjamin pekerjaan seperti yang diharapkan. Ironisnya lagi, serbuan tenaga kerja asing yang merangsek ke negeri ini meningkat dengan begitu tajam. Menurut data Depnakertrans, pada tahun 2004 hanya ada 19.567 ekspatriat di negeri ini. Tetapi di akhir tahun 2005, jumlahnya sudah mencapai lebih dari 51 ribu. Sebanyak $59,86 \%$ dari jumlah tersebut menduduki jabatan profesional.

Perguruan tinggi hadir sebagai institusi pembangun linkage antara dunia sekolah dan dunia kerja. Perguruan tinggi menjadi jembatan yang mempersiapkan lulusan sekolah dasar-menengah menjadi personel yang siap pakai dan siap diberdayakan. Lulusan perguruan tinggi dituntut untuk bisa meningkatkan value added perusahaan dengan menggunakan sumberdaya internal secara optimal serta memberikan feedback demi perbaikan perusahaan. Sayangnya, perguruan-perguruan tinggi di Indonesia tidaklah sama kualitasnya.

Banyak perusahaan yang mengaku telah membatasi varians mutu lulusan dengan mengontrol beberapa variabel, seperti IPK di atas 3, akan tetapi hasil tes internal perusahaan menunjukkan bahwa varians mutu lulusan tetap lebar. Akibatnya lagi, ada lulusan-lulusan yang berkualitas tetapi masih menganggur; dan ada pula lulusan-lulusan yang "biasa-biasa saja" tetapi sukses mendapat pekerjaan dan memberi "value added" yang destruktif bagi perusahaan. Berikut adalah yang mempengaruhi mutu lulusan ${ }^{[1]}$ :

1. Kualitas input

2. Kualitas dan kuantitas dosen

3. Sistem penilaian

4. Teaching materials

5. Kerjasama

6. Kepercayaan diri

7. Komunikasi efektif

8. Pengetahuan praktis

9. Presentasi dan kemampuan meyakinkan orang lain

10. Leadership 
11. Keberanian dan etika

12. Pengetahuan bisnis lemah

13. Kemampuan Bahasa Inggris

\subsection{Penerimaan Calon Karyawan Dalam Perusahaan}

Pada umumnya, setiap perusahaan memiliki bagian yang disebut divisi personalia atau divisi Sumber Daya Manusia (SDM) atau divisi Human Resources and Develompment (HRD) dimana salah satu fungsinya adalah pengadaan (rekrutmen) tenaga kerja. Proses rekrutmen biasanya melalui beberapa tahapan terurut, meliputi penyeleksian surat lamaran kerja, tes tertulis, psikotes, dan wawancara. Pada tahapan pertama yaitu penyeleksian surat lamaran, terdapat banyak titik/criteria yang diperhatikan HRD. Namun pada umumnya untuk surat lamaran kerja yang datang dari pelamar lulusan S1 fresh graduate, terdapat 10 kriteria yang paling diperhitungkan dalam proses seleksi tersebut, yaitu:

1. Nama Besar Perguruan Tinggi

2. Kemampuan Bahasa Inggris

3. Penampilan

4. Indeks Prestasi Komulatif

5. Alamat / Tempat Menginap

6. Pengalaman Magang

7. Kemampuan Aplikasi Komputer

8. Pengalaman Organisasi

9. Kesesuaian Program Studi dengan Posisi Kerja

10. Jenis Kelamin

Diantara kesepuluh kriteria tersebut terdapat beberapa kriteria yang paling diutamakan antara perusahaan yang dengan yang lainnya berbeda, atau dengan kata lain setiap perusahaan mempunyai skala prioritas tersendiri terhadap beberapa criteria tersebut sesuai dengan kebijaksanaan perusahaan itu sendiri ${ }^{[4]}$.

\subsection{Multidimensional Unfolding (MDU)}

Multidimensional Unfolding (MDU) digunakan untuk menganalisa kedekatan antar objek (individu dan atribut) berdasarkan nilai yang diberikan tiap individu mengenai tiap atribut. Biasanya, data dalam MDU bersifat peringkat (ordinal) kesukaan dari individu berbeda mengenai satu set atribut. Tiap individu dianggap sebagai titik "ideal" dalam ruang MDU sedemikian hingga jarak antar tiap titik ideal dengan titik atribut menggambarkan nilai kesukaaannya. Kata unfolding dipakai karena metode ini mencoba untuuk membentangkan (unfold) data matriks two-mode (matriks dengan kategori baris dan kolom yang berbeda) menjadi matriks one-mode (matriks dengan kategori baris dan kolom sama). Kategori baris maupun kolom matriks one-mode yang terbentuk merupakan gabungan dari kategori dan baris dari matriks two-mode.

Sebagai contoh diberikan matriks two-mode dengan entri berupa proximities antara 6 individu dengan 4 atribut seperti terlihat pada Tabel 1. Sedangkan dalam unfolding matriks proximities tersebut dibentangkan menjadi matriks one-mode, sehingga Tabel 1 dibentangkan menjadi Tabel 2. 
Tabel 1. Contoh Matriks Proximities Two-mode

\begin{tabular}{|c|c|c|c|c|}
\hline & $\mathrm{A}$ & $\mathrm{B}$ & $\mathrm{C}$ & $\mathrm{D}$ \\
\hline 1 & $\mathrm{p}_{1 \mathrm{~A}}$ & $\mathrm{p}_{1 \mathrm{~B}}$ & $\mathrm{p}_{1 \mathrm{C}}$ & $\mathrm{p}_{1 \mathrm{D}}$ \\
\hline 2 & $\mathrm{p}_{2 \mathrm{~A}}$ & $\mathrm{p}_{2 \mathrm{~B}}$ & $\mathrm{p}_{2 \mathrm{C}}$ & $\mathrm{p}_{2 \mathrm{D}}$ \\
\hline 3 & $\mathrm{p}_{3 \mathrm{~A}}$ & $\mathrm{p}_{3 \mathrm{~B}}$ & $\mathrm{p}_{3 \mathrm{C}}$ & $\mathrm{p}_{3 \mathrm{D}}$ \\
\hline 4 & $\mathrm{p}_{4 \mathrm{~A}}$ & $\mathrm{p}_{4 \mathrm{~B}}$ & $\mathrm{p}_{4 \mathrm{C}}$ & $\mathrm{p}_{4 \mathrm{D}}$ \\
\hline 5 & $\mathrm{p}_{5 \mathrm{~A}}$ & $\mathrm{p}_{5 \mathrm{~B}}$ & $\mathrm{p}_{5 \mathrm{C}}$ & $\mathrm{p}_{5 \mathrm{D}}$ \\
\hline 6 & $\mathrm{p}_{6 \mathrm{~A}}$ & $\mathrm{p}_{6 \mathrm{~B}}$ & $\mathrm{p}_{6 \mathrm{C}}$ & $\mathrm{p}_{6 \mathrm{D}}$ \\
\hline
\end{tabular}

Tabel 2. Contoh Matriks Proximities One-mode

\begin{tabular}{|c|c|c|c|c|c|c|c|c|c|c|}
\hline & $\mathrm{A}$ & $\mathrm{B}$ & $\mathrm{C}$ & $\mathrm{D}$ & 1 & 2 & 3 & 4 & 5 & 6 \\
\hline $\mathrm{A}$ & - & - & - & - & $\mathrm{p}_{1 \mathrm{~A}}$ & $\mathrm{p}_{2 \mathrm{~A}}$ & $\mathrm{p}_{3 \mathrm{~A}}$ & $\mathrm{p}_{4 \mathrm{~A}}$ & $\mathrm{p}_{5 \mathrm{~A}}$ & $\mathrm{p}_{6 \mathrm{~A}}$ \\
\hline $\mathrm{B}$ & - & - & - & - & $\mathrm{p}_{1 \mathrm{~B}}$ & $\mathrm{p}_{2 \mathrm{~B}}$ & $\mathrm{p}_{3 \mathrm{~B}}$ & $\mathrm{p}_{4 \mathrm{~B}}$ & $\mathrm{p}_{5 \mathrm{~B}}$ & $\mathrm{p}_{6 \mathrm{~B}}$ \\
\hline $\mathrm{C}$ & - & - & - & - & $\mathrm{p}_{1 \mathrm{C}}$ & $\mathrm{p}_{2 \mathrm{C}}$ & $\mathrm{p}_{3 \mathrm{C}}$ & $\mathrm{p}_{4 \mathrm{C}}$ & $\mathrm{p}_{5 \mathrm{C}}$ & $\mathrm{p}_{6 \mathrm{C}}$ \\
\hline $\mathrm{D}$ & - & - & - & - & $\mathrm{p}_{1 \mathrm{D}}$ & $\mathrm{p}_{2 \mathrm{D}}$ & $\mathrm{p}_{3 \mathrm{D}}$ & $\mathrm{p}_{4 \mathrm{D}}$ & $\mathrm{p}_{5 \mathrm{D}}$ & $\mathrm{p}_{6 \mathrm{D}}$ \\
\hline 1 & $\mathrm{p}_{1 \mathrm{~A}}$ & $\mathrm{p}_{1 \mathrm{~B}}$ & $\mathrm{p}_{1 \mathrm{C}}$ & $\mathrm{p}_{1 \mathrm{D}}$ & - & - & - & - & - & - \\
\hline 2 & $\mathrm{p}_{2 \mathrm{~A}}$ & $\mathrm{p}_{2 \mathrm{~B}}$ & $\mathrm{p}_{2 \mathrm{C}}$ & $\mathrm{p}_{2 \mathrm{D}}$ & - & - & - & - & - & - \\
\hline 3 & $\mathrm{p}_{3 \mathrm{~A}}$ & $\mathrm{p}_{3 \mathrm{~B}}$ & $\mathrm{p}_{3 \mathrm{C}}$ & $\mathrm{p}_{3 \mathrm{D}}$ & - & - & - & - & - & - \\
\hline 4 & $\mathrm{p}_{4 \mathrm{~A}}$ & $\mathrm{p}_{4 \mathrm{~B}}$ & $\mathrm{p}_{4 \mathrm{C}}$ & $\mathrm{p}_{4 \mathrm{D}}$ & - & - & - & - & - & - \\
\hline 5 & $\mathrm{p}_{5 \mathrm{~A}}$ & $\mathrm{p}_{5 \mathrm{~B}}$ & $\mathrm{p}_{5 \mathrm{C}}$ & $\mathrm{p}_{5 \mathrm{D}}$ & - & - & - & - & - & - \\
\hline 6 & $\mathrm{p}_{6 \mathrm{~A}}$ & $\mathrm{p}_{6 \mathrm{~B}}$ & $\mathrm{p}_{6 \mathrm{C}}$ & $\mathrm{p}_{6 \mathrm{D}}$ & - & - & - & - & - & - \\
\hline
\end{tabular}

Terlihat pada Tabel 2, banyak data yang tidak tersedia pada proximities antar indiviu dan antar atribut. Hal inilah yang menjadi tantangan dalam MDU untuk dapat menemukan konfigurasi titik-titik atribut dalam suatu ruang berdimensi rendah yang merepresentasikan nilai proxomitiesnya.

Multidimensional Unfolding (MDU) kadang disebut multidimensional scaling dengan data diagonal matriks kosong. Hal ini karena ukuran kemiripan antara $\mathrm{n}$ baris individu dengan $m$ kolom atribut disajikan dalam matriks $(n+m) \times(n+m)$ matriks. Data yang diperoleh berupa data preferensi (kesukaan) $\delta_{\mathrm{ij}}$ yang menunjukkan seberapa besar individu tidak suka atribut $\mathrm{j}$.

Jika diasumsikan bahwa proximity adalah dissimilarity dan tidak ada transformasi data, maka dipunyai matriks partisi $\mathbf{W}$ dengan bobot $\mathrm{w}_{\mathrm{ij}}$,

$$
\left[\begin{array}{ll}
W_{11} & W_{12} \\
W_{12}^{\prime} & W_{22}
\end{array}\right]=\left[\begin{array}{cc}
0 & W_{12} \\
W_{12}^{\prime} & 0
\end{array}\right]
$$

dan matriks $\mathrm{X}$ terpartisi dalam $\mathbf{X}_{\mathbf{1}}$ untuk $\mathrm{n}_{1}$ individu dan $\mathbf{X}_{\mathbf{2}}$ untuk $\mathrm{n}_{2}$ obyek. Karena himpunan proximity adalah kosong maka $\mathbf{W}_{\mathbf{1 1}}=\mathbf{0}$ dan $\mathbf{W}_{\mathbf{2 2}}=\mathbf{0}$. Dan bobot matriks dapat digunakan dalam program MDS untuk mengerjakan unfolding. Selanjutnya untuk menyelesaikan Multidimensional Unfolding digunakan algoritma Smacof sebagai berikut:

1. Menetapkan $Z=X^{[0]}$, dimana $X^{[0]}$ merupakan konfigurasi awal yang boleh disusun secara random / tidak. Menetapkan $\mathrm{k}=0$ dan $\in$ adalah konstanta positif bernilai kecil.

2. Menghitung $\sigma_{\mathrm{r}}^{[0]}=\sigma_{\mathrm{r}}\left(\mathrm{X}^{[0]}\right)$, kemudian menetapkan $\sigma_{\mathrm{r}}^{[-1]}=\sigma_{\mathrm{r}}^{[0]}$

$$
\sigma_{r}(X)=\sum_{i<j} w_{i j}\left(\delta_{i j}-d_{i j}(X)\right)^{2}
$$

Dengan: $\delta_{\mathrm{ij}}$ merupakan nilai ketidakmiripan (dissimilarity) antara dua objek $\mathrm{d}_{\mathrm{ij}}(\mathrm{X})$ merupakan jarak euclidean antar dua objek dalam peta 
$\mathrm{W}_{\mathrm{ij}}$ merupakan pembobot yang bernilai 1 jika $\delta_{\mathrm{ij}}$ diketahui

0 jika $\delta_{\mathrm{ij}}$ tidak diketahui

atau $\sigma_{\mathrm{r}}(\mathrm{X})=\eta_{\delta}^{2}+\operatorname{tr}\left(\mathbf{X}^{\prime} \mathbf{V} \mathbf{X}\right)-2 \operatorname{tr}\left(\mathbf{X}^{\prime} \mathbf{B}(\mathbf{X}) \mathbf{X}\right)$

$$
\begin{aligned}
& \text { dengan } \mathbf{V}=\left[\begin{array}{ccc}
w_{12}+w_{13} & -w_{12} & -w_{13} \\
-w_{12} & w_{12}+w_{23} & -w_{23} \\
-w_{13} & -w_{23} & w_{13}+w_{23}
\end{array}\right] \\
& \mathbf{B}(\mathbf{X})=\left[\begin{array}{ll}
B_{11}(X) & B_{12}(X) \\
B_{12}(X)^{\prime} & B_{22}(X)
\end{array}\right] \text { yang terdiri dari elemen-elemen: }
\end{aligned}
$$

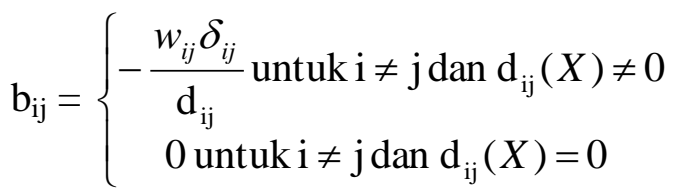

$$
\begin{aligned}
& \mathrm{b}_{\mathrm{ii}}=-\sum_{j=1, j \neq i}^{n} b_{i j}
\end{aligned}
$$

3. Saat $\mathrm{k}=0$ atau $\sigma_{\mathrm{r}}^{[\mathrm{k}-1]}-\sigma_{\mathrm{r}}^{[\mathrm{k}]}>\in$ dan $\mathrm{k} \leq$ angka iterasi maksimum

4. Menambah nilai iterasi $\mathrm{k}$ dengan 1

5. Menghitung Guttman transform $X^{[\mathrm{k}]}$

$$
\text { dengan } \begin{aligned}
\mathbf{X}_{\mathbf{1}}{ }^{\mathbf{u}} & =\left[\mathbf{V}^{-}\right]_{11}\left[\mathbf{B}_{11}(\mathbf{X}) \mathbf{X}_{\mathbf{1}}+\mathbf{B}_{\mathbf{1 2}}(\mathbf{X}) \mathbf{X}_{\mathbf{2}}\right] \\
\mathbf{X}_{\mathbf{2}}{ }^{\mathbf{u}} & =\left[\mathbf{V}^{-}\right]_{22}\left[\mathbf{B}_{\mathbf{1 2}}(\mathbf{X})^{\prime} \mathbf{X}_{\mathbf{1}}+\mathbf{B}_{\mathbf{2 2}}(\mathbf{X}) \mathbf{X}_{\mathbf{2}}\right]
\end{aligned}
$$

6. Menghitung $\sigma_{\mathrm{r}}^{[\mathrm{k}]}=\sigma_{\mathrm{r}}\left(\mathrm{X}^{[\mathrm{k}]}\right)$

7. Menetapkan $\mathrm{Z}=\mathrm{X}^{[\mathrm{k}]}$

8. Selesai

$\mathbf{X}_{\mathbf{1}}{ }^{\mathbf{u}}$ dan $\mathbf{X}_{\mathbf{2}}{ }^{\mathbf{u}}$ sendiri merupakan update hasil konfigurasi koordinat untuk atribut dan individu dengan nilai Stress yang menurun setiap iterasi ${ }^{[2]}$. Stress merupakan ukuran badness-of-fit dari suatu model MDS. Stress merupakan selisih diantara proximities dengan jarak yang dihasilkan. Stress menyatakan indeks seberapa buruknya jarak antara i dan j dalam konfigurasi yang dihasilkan dari nilai kedekatan dalam data. Sehingga jika nilai Stress semakin kecil atau mendekati nol, maka semakin baik model MDS yang diperoleh. Nilai Stress juga dipakai dalam multidimensional unfolding untuk mengetahui ketepatan dari konfigurasi yang dihasilkan. Rumus Stress yang digunakan adalah normalized Sterss $\sigma_{\mathrm{n}}(\mathrm{X})$ dari Kruskal yaitu:

$$
\sigma_{n}(X)=\frac{\sum_{i<j} w_{i j}\left(\delta_{i j}-d_{i j}(X)\right)^{2}}{\sum_{i<j} w_{i j} \delta_{i j}^{2}}
$$

dengan kriteria kondisi Stress menurut Kruskal sebagai berikut ${ }^{[6]}$ :

Tabel 3. Nilai Stress untuk MDU

\begin{tabular}{|c|c|}
\hline Stress (\%) & Kondisi \\
\hline 20,00 & Jelek \\
\hline 10,00 & Cukup \\
\hline 5,00 & Baik \\
\hline 2,50 & Sangat Baik \\
\hline 0,00 & Sempurna \\
\hline
\end{tabular}




\section{Metode Penelitian}

Penelitian ini dilakukan di Kabupaten Batang, dengan mengambil sampel untuk 71 perusahaan. Pengambilan datanya dilakukan dengan wawancara langsung kepada bagian Human Resources and Development (HRD) dari suatu badan usaha / perusahaan. Sedangkan pengolahan datanya digunakan multidimensional unfolding dengan SPSS 16.

Langkah-langkah dalam penelitian:

1. Mengumpulkan Data

Variabel-variabel yang digunakan dalam penelitian analisis persepsi kerja terhadap lulusan perguruan tinggi fresh graduate S1 menggunakan multidimensional scaling ini adalah:

1. Nama Perusahaan

2. Nama Besar Perguruan Tinggi

3. Kemampuan Bahasa Inggris

4. Penampilan

5. Indeks Prestasi Komulatif

6. Alamat / Tempat Menginap

7. Pengalaman Magang

8. Kemampuan Aplikasi Komputer

9. Pengalaman Organisasi

10. Kesesuaian Program Studi dengan Posisi Kerja

11. Jenis Kelamin

Untuk variabel 2 sampai 11 digunakan skala ordinal, perusahaan hanya menjawab dengan menggunakan jawaban 1 sampai 10 , yaitu 1 = paling diutamakan dan $10=$ paling tidak diutamakan .

2. Mengolah dan Menganalisis

Setelah data preferensi diolah, dilakukan analisis output. Pertama mencari rata-rata akumulasi jarak antara semua individu dalam satu kategori dengan setiap atribut sehingga dapat diurutkan dari yang terkecil sampai yang terbesar. Analisis ini bertujuan untuk mengetahui urutan kriteria awal pelamar dari yang paling diutamakan sampai dengan kriteria yang paling tidak diutamakan perusahaan pada setiap kategori. Kedua adalah mencari variabilitas tiap kategori yaitu mencari rata-rata akumulasi setiap jarak antar individu dalam tiap kategori. Analisis ini bertujuan untuk mengetahui kekompakan anggota suatu kategori. Dengan semakin rendah nilai variabilitas suatu kategori, semakin kuat pula kekompakan anggotanya dalam menjadi suatu kelompok. Analisis pertama dan kedua dilakukan pada setiap pembagian kategori, yaitu berdasarkan bidang usahanya, berdasarkan lokasinya dan gabungan dari kedua pembagian tersebut.

3. Menghitung Nilai Stress

Stress merupakan ukuran badness-of-fit dari suatu model MDU

\section{Hasil dan Pembahasan}

Pada analisis multidimensional unfolding dengan menggunakan variabel nama besar perguruan tinggi, kemampuan bahasa inggris, penampilan, indeks prestasi komulatif, alamat/tempat menginap, pengalaman magang, kemampuan aplikasi komputer, pengalaman organisasi, kesesuaian program studi dengan posisi kerja, jenis kelamin yang merupakan kriteria awal yang dipertimbangkan perusahaan ketika akan merekrut lulusan S1 fresh graduate, dengan menggunakan SPSS 16, dan nilai dari penalty, yaitu lambda $=0,5$ dan omega $=1,0$, terlihat pada Tabel 4 dan 5 bahwa algoritma konvergen 
setelah iterasi ke 244 dengan nilai stress 0,2075 , yang berarti walaupun jelek penyelesaian sesuai dengan data. Selanjutnya nilai Variasi Proximities adalah 0,5504819 dan nilai Variasi Transformed Proximities adalah 0,5777352, ini berarti nilai variasi proximities transformasi hampir sama dengan nilai variasi proximities yang asli. Kemudian nilai Sumof-Squares of DeSarbo's Intermixedness Indices adalah 0,2091094 yang berarti penyelesaian titik-titik dari himpunan yang berbeda jauh lebih baik dan nilai Shepard's Rough Nondegeneracy Index adalah 0, 7799687, yaitu persentase jarak yang berbeda hampir $80 \%$.

Tabel 4. Nilai Stress dengan lambda $=0,5$ dan omega $=1,0$

\begin{tabular}{|c|c|c|c|c|}
\hline Iteration & Penalized Stress & Difference & Stress & Penalty \\
\hline 0 & .9581986 & & .4349106 & 2.1111111 \\
244 & .6486107 & $.0000006^{\mathrm{a}}$ & .2075940 & 2.0265321 \\
\hline
\end{tabular}

a. Difference in consecutive penalized Stress values less than the DIFFSTRESS criterion.

Tabel 5. Ukuran-Ukuran dalam MDU dengan lambda $=0,5$ dan omega $=1,0$

\begin{tabular}{|ll|c|}
\hline Iterations & & 244 \\
Final Function Value & .6486107 \\
Function Value & Stress Part & .2075940 \\
Parts & Penalty Part & 2.0265321 \\
Badness of Fit & Normalized Stress & .0428011 \\
& Kruskal's Stress-I & .2068842 \\
& Kruskal's Stress-II & .5551470 \\
& Young's S-Stress-I & .3064272 \\
Goodness of Fit & Young's S-Stress-II & .4777362 \\
& Dispersion Accounted For & .9571989 \\
& Variance Accounted For & .7975616 \\
& Recovered Preference Orders & .7602504 \\
Variation & Spearman's Rho & .8168352 \\
Coefficients & Kendall's Tau-b & .7211178 \\
& Variation Proximities & .5504819 \\
& Variation Transformed & .5777352 \\
Degeneracy & Proximities & .4838271 \\
Indices & Variation Distances & .2091094 \\
& Sum-of-Squares of DeSarbo's & \\
& Intermixedness Indices & .7799687 \\
\hline
\end{tabular}

Selanjutnya dibuat plot kedekatan badan usaha dan kriteria awal yang dipertimbangkan perusahaan ketika akan merekrut lulusan fresh graduate $\mathrm{S} 1$ terlihat pada Gambar 1. 


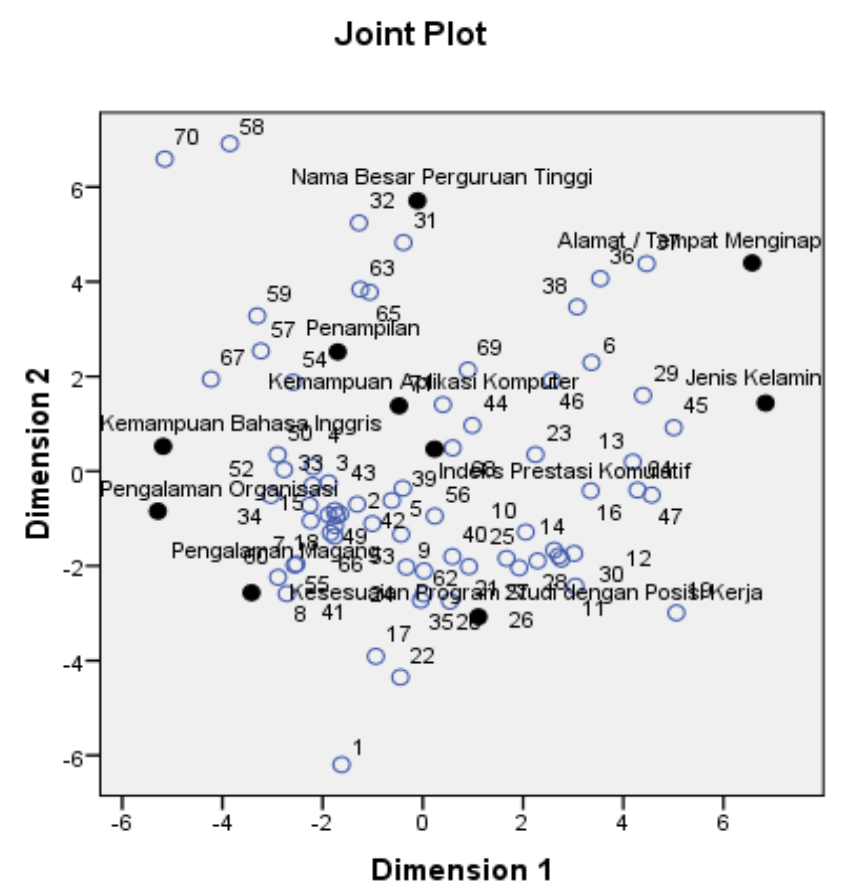

Gambar 1. Badan Usaha dan Kriteria Awal yang Dipertimbangkan Perusahaan Ketika Merekrut Lulusan Fresh Graduate S1

Terlihat pada Gambar 1 bahwa sebagian perusahaan/badan usaha di kabupaten Batang dalam merekrut karyawan baru yang dari lulusan fresh graduate S1 kebanyakan mengutamakan kesesuaian program studi dengan posisi kerja, indeks prestasi kumulatif (IPK), pengalaman magang dan kemampuan aplikasi komputer. Seperti terlihat badan usaha yang jaraknya dekat dengan:

1. kesesuaian program studi dengan posisi kerja adalah badan usaha no 20, 35, 21, 62

2. IPK adalah badan usaha no $68,44,71,39$

3. pengalaman magang adalah badan usaha no $7,8,41,55,60$

4. penampilan adalah badan usaha no $54,57,65$

5. kemampuan aplikasi komputer adalah badan usaha no 44, 71, 69

Sedangkan kemampuan bahasa Inggis, nama besar perguruan tinggi, pengalaman organisasi, alamat/tempat menginap dan jenis kelamin kurang diutamakan oleh perusahaan/badan usaha di Kabupaten Batang. Hal ini dapat dilihat pada tabel transformed proximities.

Dari tabel transformed proximities dibuat urutan dari no 1 yaitu yang paling diutamakan sampai no 10 yang paling tidak diutamakan oleh perusahaan/badan usaha di Kabupaten Batang dalam merekrut karyawan dari lulusan fresh graduate S1 dengan melihat urutan jumlah nilai dari paling kecil ke paling besar. Tabel urutan tersebut seperti terlihat pada Tabel 7. 
Tabel 7. Urutan Yang Paling Diutamakan Perusahaan / Badan Usaha di Kabupaten Batang dalam Merekrut Karyawan dari Lulusan Fresh Graduate S1

\begin{tabular}{|c|c|l|}
\hline Urutan & Jumlah Nilai & \multicolumn{1}{c|}{ Kriteria Awal Pelamar } \\
\hline 1 & 204 & IPK \\
\hline 2 & 282 & Kemampuan Aplikasi Komputer \\
\hline 3 & 312 & Kesesuaian Program Studi dengan Posisi Kerja \\
\hline 4 & 344 & Penampilan \\
\hline 5 & 267 & Pengalaman Magang \\
\hline 6 & 434 & Kemampuan Bahasa Inggris \\
\hline 7 & 457 & Pengalaman Organisasi \\
\hline 8 & 481 & Nama besar perguruan tinggi \\
\hline 9 & 493 & Jenis Kelamin \\
\hline 10 & 531 & Alamat /tempat menginap \\
\hline
\end{tabular}

\section{Kesimpulan}

Dari hasil analisis didapat hasil bahwa:

1. Nilai stress 0,2075, yang berarti walaupun jelek penyelesaian sesuai dengan data. Selain itu nilai variasi proximities hampir sama dengan nilai variasi yang asli.

2. Urutan kriteria yang paling diutamakan perusahaan/badan usaha di kabupaten Batang dalam merekrut karyawan baru yang dari lulusan fresh graduate S1 adalah: IPK, kemampuan aplikasi komputer, kesesuaian program studi dengan posisi kerja, penampilan, pengalaman magang, kemampuan bahasa Inggris, pengalaman organisasi, nama besar Perguruan Tinggi, jenis kelamin dan alamat/tempat menginap.

\section{DAFTAR PUSTAKA}

1. Anonim, Lulusan Jaman Sekarang, 2006, URL: http://nofieiman.com/.

2. Borg, I. and Patrick, J.F, Theory and Application: Modern Multidimensional Scaling, Springer Verlag, New York, 1998.

3. Dillon, W.R. and Goldstein, M., Methods and Applications Multivariate Analysis, John Wiley \& Sons, Inc., New York, 1984.

4. Formasoo, A., Survei Tempo 2007: Sepuluh Kampus Impian Dunia Kerja, 2007, URL: http://blog.its.ac.id/kurnianto.

5. Johnson, R.A., and Wichern, D.W., Applied Multivariate Statistical Analysis, Third Edition, Prentice-Hall of India Private Limited, New Delhi, 1996.

6. Bagus Sartono, dkk, Buku Ajar Analisis Peubah Ganda, Jurusan Statistika FMIPA IPB, Bogor, 2003. 